\title{
Ruthenium Complexes of 2-[(4-(Arylamino)phenyl)azo]pyridine Formed via Regioselective Phenyl Ring Amination of Coordinated 2-(Phenylazo)pyridine: Isolation of Products, X-ray Structure, and Redox and Optical Properties
}

\author{
Chayan Das, ${ }^{\dagger}$ Amrita Saha, ${ }^{\dagger}$ Chen-Hsiung Hung, ${ }^{\ddagger}$ Gene-Hsiang Lee,${ }^{\S}$ Shie-Ming Peng,,${ }^{\S}$ and \\ Sreebrata Goswami*, \\ Department of Inorganic Chemistry, Indian Association for the Cultivation of Science, \\ Kolkata 700 032, India, Department of Chemistry, National Changhua University of Education, \\ Changhua, Taiwan 500, Republic of China, and Department of Chemistry, National Taiwan \\ University, Taipei, Taiwan, Republic of China \\ Received May 29, 2002
}

\begin{abstract}
Aromatic ring amination reactions in the ruthenium complex of 2-(phenylazo)pyridine is described. The substitutionally inert cationic brown complex $\left[\mathrm{Ru}(\text { pap })_{3}\right]\left(\mathrm{ClO}_{4}\right)_{2}$ (1) (pap $=2$-(phenylazo)pyridine) reacts smoothly with aromatic amines neat and in the presence of air to produce cationic and intense blue complexes $\left[\mathrm{Ru}\left(\mathrm{HL}^{2}\right)_{3}\right]\left(\mathrm{ClO}_{4}\right)_{2}(2)\left(\mathrm{HL}^{2}\right.$ $=2-[(4-($ arylamino $)$ phenyl)azo]pyridine). These were purified on a preparative TLC plate. The X-ray structure of the new and representative complex $2 \mathrm{c}$ has been solved to characterize them. The results are compared with those of the starting complex, $\left[\mathrm{Ru}(\mathrm{pap})_{3}\right]\left(\mathrm{ClO}_{4}\right)_{2}(1)$. The transformation $1 \rightarrow 2$ involves aromatic ring amination at the para carbon (with respect to the diazo function) of the pendant phenyl rings of all three coordinated pap ligands in 1. The transformation is stereoretentive, and the amination reaction is regioselective. The extended ligand $\mathrm{HL}^{2}$ coordinates as a bidentate ligand and chelates to ruthenium(II) through the pyridine and one of the azo nitrogens. The amine nitrogen of this bears a hydrogen atom and remains uncoordinated. Similarly, the amination reaction on the mixed-ligand complex $\left[\mathrm{Ru}\left(\right.\right.$ pap) $\left.(\mathrm{bpy})_{2}\right]\left(\mathrm{ClO}_{4}\right)_{2}$ produces the blue complex $\left[\mathrm{Ru}\left(\mathrm{HL}^{2}\right)(\mathrm{bpy})_{2}\right]\left(\mathrm{ClO}_{4}\right)_{2}(3)$ as anticipated. The reactions of $\left[\mathrm{RuCl}_{2}(\mathrm{dmsO})_{4}\right]$ and $\left[\mathrm{Ru}(\mathrm{S})_{2}(\mathrm{~L})_{2}\right]^{2+}$ (dmso = dimethyl sulfoxide, $\mathrm{S}=$ labile coordinated solvent, $\mathrm{L}$ $=2,2^{\prime}$-bipyridine (bpy) and pap) with the preformed $\mathrm{HL}^{2}$ ligand have been explored. The structure of the representative complex $\left[\mathrm{RuCl}_{2}\left(\mathrm{HL}^{2 \mathrm{a}}\right)_{2}\right](5 \mathrm{a})$ is reported. It has the chlorides in trans configuration while the pyridine as well as azo nitrogens are in cis geometry. Optical spectra and redox properties of the newly synthesized complexes are reported. All the ruthenium complexes of $\mathrm{HL}^{2}$ are characterized by their intense blue solution colors. The lowest energy transitions in these complexes appear near $600 \mathrm{~nm}$, which have been attributed to intraligand charge-transfer transitions. For example, the lowest energy visible range transition in $\left[\mathrm{Ru}\left(\mathrm{HL}^{2 b}\right)_{3}\right]^{2+}$ appears at $602 \mathrm{~nm}$ and its intensity is $65510 \mathrm{M}^{-1} \mathrm{~cm}^{-1}$. All the tris chelates show multiple-step electron-transfer processes. In $\left[\mathrm{Ru}\left(\mathrm{HL}^{2}\right)_{3}\right]^{2+}$, six reductions waves constitute the complete electron-transfer series. The electrons are believed to be added successively to the three azo functions. In the mixed-ligand chelates $\left[\mathrm{Ru}\left(\mathrm{HL}^{2}\right)(\mathrm{pap})_{2}\right]^{2+}$ and $\left[\mathrm{Ru}\left(\mathrm{HL}^{2}\right)(\mathrm{bpy})_{2}\right]^{2+}$ the reductions due to $\mathrm{HL}^{2}$, pap, and bpy are observed.
\end{abstract}

\section{Introduction}

This work originated from our recent interest on metalpromoted aromatic ring amination reactions ${ }^{1-4}$ on the

* To whom correspondence should be addressed. E-mail: icsg@ mahendra.iacs.res.in. Fax: (+91) 33-473 2805.

$\dagger$ Indian Association for the Cultivation of Science.

$\doteqdot$ National Changhua University of Education.

$\S$ National Taiwan University. coordinated ligand 2-(phenylazo)pyridine (abbreviated as pap). Amine fusion reactions of the above type occurring either at ortho or at para carbon (relative to the azo fragment) of the pendent phenyl ring (Scheme 1) were observed. For example, when a labile $\left[\mathrm{Co}^{\mathrm{II}}(\mathrm{pap})_{3}\right]^{2+}$ complex was reacted with $\mathrm{ArNH}_{2}$, it produced ${ }^{3}$ a green cobalt(III) complex, $\left[\mathrm{Co}\left(\mathrm{L}^{1}\right)_{2}\right]^{+}$. This transformation involves elimination of a 
Scheme 1

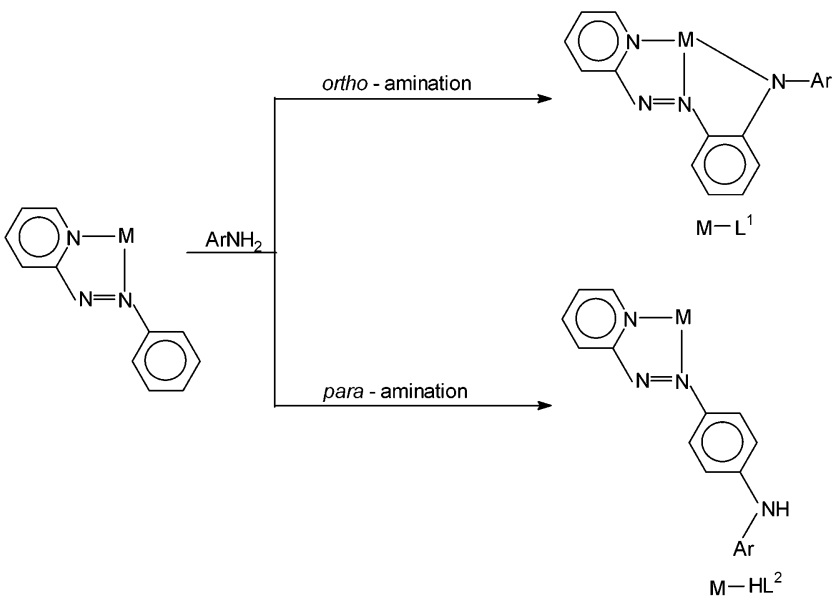

bidentate pap ligand from $\left[\mathrm{Co}(\mathrm{pap})_{3}\right]^{2+}$, which is followed by ortho-amination of the rest two coordinated pap ligands. It is to be noted here that ortho-amination of the ligand pap leads to the formation of a bis-chelating tridentate anionic ligand $\left[\mathrm{L}^{1}\right]^{-}$, two of which are coordinated to the cobalt(III) cation in its complex. It thus appeared to us that ligand dissociation from the mediator complex might be responsible for the above ortho-amination reaction. We thought it worthwhile to study the above amination reaction using the mediator metal complexes of different labilities to look for the possible role of the metal complex in the site selectivity of the above reaction. Although complete ortho-amination reaction was observed in the case of $\left[\mathrm{Co}(\mathrm{pap})_{3}\right]^{2+}$, we did not have an example of complete para-amination reactions. We, however, were successful to observe ${ }^{1,5}$ the para-amination reactions, only partially, in the cases of a rhodium(III) and a chromium(II) complex. The results of the above reactions indicated that a cationic metal complex of pap, which is absolutely inert toward substitution, might be suitable for a complete regioselective para-amination reaction. To achieve this objective we chose a cationic tris-chelate $\left[\mathrm{Ru}(\mathrm{pap})_{3}\right]$ $\left(\mathrm{ClO}_{4}\right)_{2}$ as the mediator complex. The reference ruthenium complex is known ${ }^{6}$ to be substitutionally inert. The primary aim of this report is to present our results on the reaction of $\mathrm{ArNH}_{2}$ with $\left[\mathrm{Ru}(\mathrm{pap})_{3}\right]\left(\mathrm{ClO}_{4}\right)_{2}$. In this case all the coordinated pap ligands have undergone amination exclusively at the para-carbon. Isolation and complete characterization of the products follow the reactions. To have further insight into these unusual transformations, reactions using some chosen starting compounds were carried out, and these results are compared and used for conclusions.

\section{Results and Discussion}

A. Starting Complex. To study the amination reaction on coordinated pap ligand, a substitutionally inert brown

(1) Saha, A.; Ghosh, A. K.; Majumdar, P.; Mitra, K. N.; Mondal, S.; Rajak, K. K.; Falvello, L. R.; Goswami, S. Organometallics 1999, 18, 3772.

(2) Ghosh, A. K.; Majumdar, P.; Falvello, L. R.; Mustafa, G.; Goswami, S. Organometallics 1999, 18, 5086.

(3) Saha, A.; Majumder, P.; Goswami, S. J. Chem. Soc., Dalton Trans. 2000, 1703.

(4) Saha, A.; Majumdar, P.; Peng, S.-M.; Goswami, S. Eur. J. Inorg. Chem. 2000, 2631.

(5) Kamar, K. K.; Saha, A.; Castiñeiras, A.; Hung, C.-H.; Goswami, S. Inorg. Chem. 2002, 41, 4531.

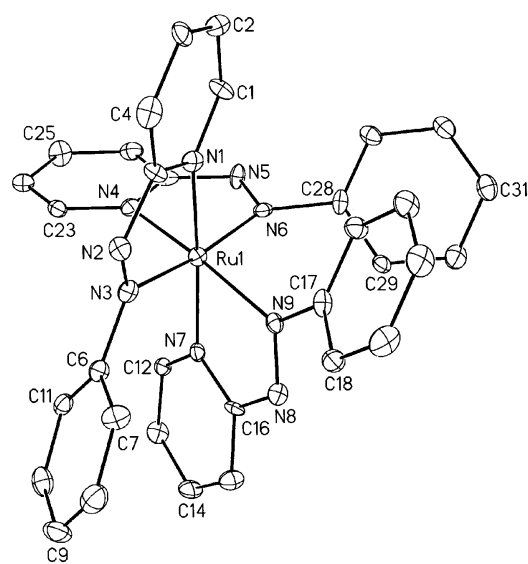

Figure 1. ORTEP representation of the cation $\left[\mathrm{Ru}(\mathrm{pap})_{3}\right]^{2+}$ in $\mathbf{1}$.

complex, $\left[\mathrm{Ru}(\mathrm{pap})_{3}\right]\left(\mathrm{ClO}_{4}\right)_{2}(\mathbf{1})$, was chosen as the reactant. The synthesis of complex 1 was first reported ${ }^{6}$ in 1983, which was subsequently modified ${ }^{7}$ by us. A high yield general and convenient method for the synthesis of $\mathbf{1}$, based on a transmetalation reaction, was reported. The ligand pap has very strong affinity toward an electron-rich ruthenium center, ${ }^{7,8}$ and the tris complexes are inert toward substitution. The structure solution of complex $\mathbf{1}$ confirms its formulation as well as its geometry. A view of the cationic part of $\mathbf{1}$ is shown in Figure 1. The coordination sphere around ruthenium is approximately octahedral involving the three pap ligands in a meridional geometry. The atomic group $\mathrm{Ru}(1)$, the three coordinated azo nitrogens $\mathrm{N}(3), \mathrm{N}(6)$, and $\mathrm{N}(9)$, and a pyridyl nitrogen, $\mathrm{N}(4)$, are nearly planar with maximum deviation of $0.1793 \AA$. Notably, the two azo nitrogens, viz. $\mathrm{N}(3)$ and $\mathrm{N}(6)$, lie trans to each other. The remaining two coordinated pyridyl nitrogens, $\mathrm{N}(1)$ and $\mathrm{N}(7)$, are also in relative trans configuration. An azo chromophore being a strong $\pi$-acceptor, trans $\mathrm{N}(\mathrm{azo})-\mathrm{M}-\mathrm{N}(\mathrm{azo})$ grouping was never observed ${ }^{8}$ before in the metal-pap complexes. However, the other possible facial isomer for the tris-chelate $\mathbf{1}$ is sterically unfavorable due to crowding of three phenyl groups. Notably, the average of $\mathrm{Ru}-\mathrm{N}$ distances (Table 1) in 1 (average 2.042(7) $\AA$ ) is shorter than that observed ${ }^{9}$ in $\left[\mathrm{Ru}\left(\mathrm{NH}_{3}\right)_{6}\right] \mathrm{I}_{2}$ (average 2.144(4) $\AA$ ). The shortness of $\mathrm{Ru}-\mathrm{N}$ bond in $\mathbf{1}$ is attributed to strong $\mathrm{d} \pi-\mathrm{p} \pi$ interactions between ruthenium $\left(\mathrm{t}_{2}\right)$ and the low-lying $\pi^{*}$ (azo) orbitals of pap. For comparison, the reference complex, $\left[\mathrm{Ru}\left(\mathrm{NH}_{3}\right)_{6}\right]^{2+}$, does not have such $\pi$ interactions. The effect of $\pi$-interactions in 1 are reflected in the long $\mathrm{N}-\mathrm{N}$ length (average 1.280(9) $\AA$ ), which is appreciably longer than that observed ${ }^{10}$ in [Hpap] $\left(\mathrm{ClO}_{4}\right)(1.258(5) \AA)$

B. Reactions and Products. In line with our synthetic strategy, complex $\mathbf{1}$ was reacted with neat $\mathrm{ArNH}_{2}$ on a steam

(6) Goswami, S.; Mukherjee, R.; Chakravorty, A. Inorg. Chem. 1983, 22, 2825.

(7) Kakoti, M.; Deb, A. K.; Goswami, S. Inorg. Chem. 1992, 31, 1302

(8) (a) Goswami, S.; Chakravarty, A. R.; Chakravorty, A. Inorg. Chem. 1983, 22, 602. (b) Goswami, S.; Chakravarty, A. R.; Chakravorty, A. Inorg. Chem. 1982, 21, 2737. (c) Goswami, S.; Chakravarty, A. R.; Chakrovorty, A. Inorg. Chem. 1981, 20, 2246.

(9) Stynes, H. C.; Ibers, J. A. Inorg. Chem. 1971, 10, 2304

(10) Saha, A.; Das, C.; Goswami, S. Indian J. Chem., Sect. A 2001, 40A, 198. 
Das et al.

Table 1. Selected Bond Lengths ( $\AA$ ) of $\mathbf{1}, \mathbf{2} \mathbf{c} \cdot \mathrm{C}_{7} \mathrm{H}_{8}$, and $\mathbf{5 a}$

\begin{tabular}{|c|c|c|c|c|c|}
\hline \multicolumn{2}{|c|}{1} & \multicolumn{2}{|c|}{$2 \mathrm{c} \cdot \mathrm{C}_{7} \mathrm{H}_{8}$} & \multicolumn{2}{|c|}{$5 a$} \\
\hline $\mathrm{Ru}(1)-\mathrm{N}(1)$ & $2.067(7)$ & $\mathrm{Ru}(1)-\mathrm{N}(1)$ & $2.058(4)$ & $\mathrm{Ru}-\mathrm{N}(1)$ & $2.071(3)$ \\
\hline $\mathrm{Ru}(1)-\mathrm{N}(3)$ & $2.056(7)$ & $\mathrm{Ru}(1)-\mathrm{N}(3)$ & $2.061(4)$ & $\mathrm{Ru}-\mathrm{N}(3)$ & $1.999(3)$ \\
\hline $\mathrm{Ru}(1)-\mathrm{N}(4)$ & $2.031(7)$ & $\mathrm{Ru}(1)-\mathrm{N}(5)$ & $2.046(4)$ & $\mathrm{Ru}-\mathrm{N}(5)$ & $2.085(3)$ \\
\hline $\mathrm{Ru}(1)-\mathrm{N}(7)$ & $2.027(7)$ & $\mathrm{Ru}(1)-\mathrm{N}(7)$ & $2.058(4)$ & $\mathrm{Ru}-\mathrm{N}(7)$ & $2.013(3)$ \\
\hline $\mathrm{Ru}(1)-\mathrm{N}(6)$ & $2.015(7)$ & $\mathrm{Ru}(1)-\mathrm{N}(9)$ & $2.073(4)$ & $\mathrm{Ru}-\mathrm{Cl}(1)$ & $2.3755(12)$ \\
\hline $\mathrm{Ru}(1)-\mathrm{N}(9)$ & $2.054(7)$ & $\mathrm{Ru}(1)-\mathrm{N}(11)$ & $2.071(4)$ & $\mathrm{Ru}-\mathrm{Cl}(2)$ & $2.3937(12)$ \\
\hline $\mathrm{N}(2)-\mathrm{N}(3)$ & $1.284(9)$ & $\mathrm{N}(2)-\mathrm{N}(3)$ & $1.296(5)$ & $\mathrm{N}(2)-\mathrm{N}(3)$ & $1.297(4)$ \\
\hline $\mathrm{N}(5)-\mathrm{N}(6)$ & $1.276(9)$ & $\mathrm{N}(6)-\mathrm{N}(7)$ & $1.285(5)$ & $\mathrm{N}(6)-\mathrm{N}(7)$ & $1.299(4)$ \\
\hline $\mathrm{N}(8)-\mathrm{N}(9)$ & $1.280(8)$ & $\mathrm{N}(10)-\mathrm{N}(11)$ & $1.287(6)$ & & \\
\hline$C(6)-C(7)$ & $1.412(11)$ & $\mathrm{N}(10)-\mathrm{C}(41)$ & $1.370(6)$ & & \\
\hline $\mathrm{C}(7)-\mathrm{C}(8)$ & $1.351(12)$ & $\mathrm{N}(11)-\mathrm{C}(42)$ & $1.427(6)$ & & \\
\hline $\mathrm{C}(8)-\mathrm{C}(9)$ & $1.398(12)$ & $\mathrm{N}(12)-\mathrm{C}(47)$ & $1.371(7)$ & & \\
\hline$C(9)-C(10)$ & $1.389(12)$ & $\mathrm{N}(12)-\mathrm{C}(48)$ & $1.425(7)$ & & \\
\hline $\mathrm{C}(10)-\mathrm{C}(11)$ & $1.378(11)$ & & & & \\
\hline$C(6)-C(11)$ & $1.369(11)$ & & & & \\
\hline
\end{tabular}

Scheme 2
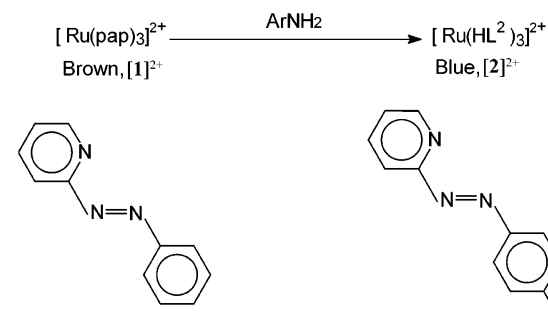

pap
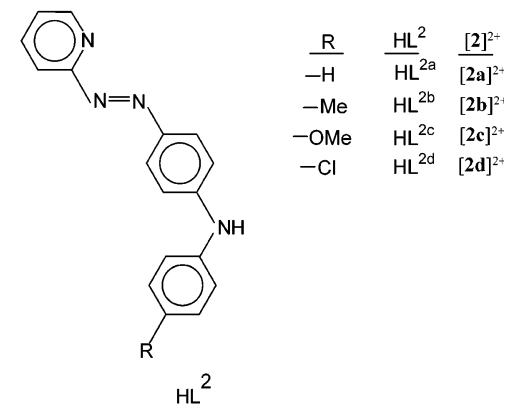

bath in air. The initial brown color of the ruthenium tris chelate $\left[\mathrm{Ru}(\text { pap })_{3}\right]\left(\mathrm{ClO}_{4}\right)_{2}$ gradually became ink-blue in $4 \mathrm{~h}$ (Scheme 2). The crude product, after initial workup, was finally purified on a preparative TLC plate. An intense blue band of composition $\left[\mathrm{Ru}\left(\mathrm{HL}^{2}\right)_{3}\right]\left(\mathrm{ClO}_{4}\right)_{2}$ (2) was collected in $60-70 \%$ yield. The above reaction does not proceed at all in the presence of solvent and is sluggish in an inert atmosphere.

A similar amination reaction was also tried on the neutral complex $^{8 \mathrm{c}}\left[\mathrm{RuCl}_{2}(\text { pap })_{2}\right]$, which notably was unreactive to $\mathrm{ArNH}_{2}$. Greater electrophilicity of the cationic complexes appears to be crucial for the amination reactions. This proposal was further strengthened by the fact that the mixedligand cationic complex ${ }^{8 \mathrm{c}}\left[\mathrm{Ru}(\mathrm{pap})(\mathrm{bpy})_{2}\right]\left(\mathrm{ClO}_{4}\right)_{2}$ (bpy $=$ 2,2'-bipyridine) reacted smoothly with $\mathrm{PhNH}_{2}$ to produce the blue complex $\left[\mathrm{Ru}\left(\mathrm{HL}^{2 \mathrm{a}}\right)(\mathrm{bpy})_{2}\right]\left(\mathrm{ClO}_{4}\right)_{2}(3)$ in a moderate yield. It is probable that nucleophilic attack of deprotonated, $[\mathrm{ArNH}]^{-}$at the para carbon of the pendant phenyl group of pap is the primary and key step for this fusion reaction. Nucleophilic substitution on an aryl ring is otherwise not common. It is believed that the phenyl ring of pap becomes electrophilic upon coordination. The hydride ion thus generated reacts with aerial oxygen to form hydroperoxide, which decomposes readily under our reaction conditions. In the aforesaid reactions, each of the coordinated pap ligands undergoes fusion with an amine function exclusively at the para-carbon (relative to the azo functionality) of the pendant phenyl ring. The results have confirmed the regioselective nature of the amination reaction. Moreover these have also demonstrated that the site selectivity of the above reactions
Scheme 3

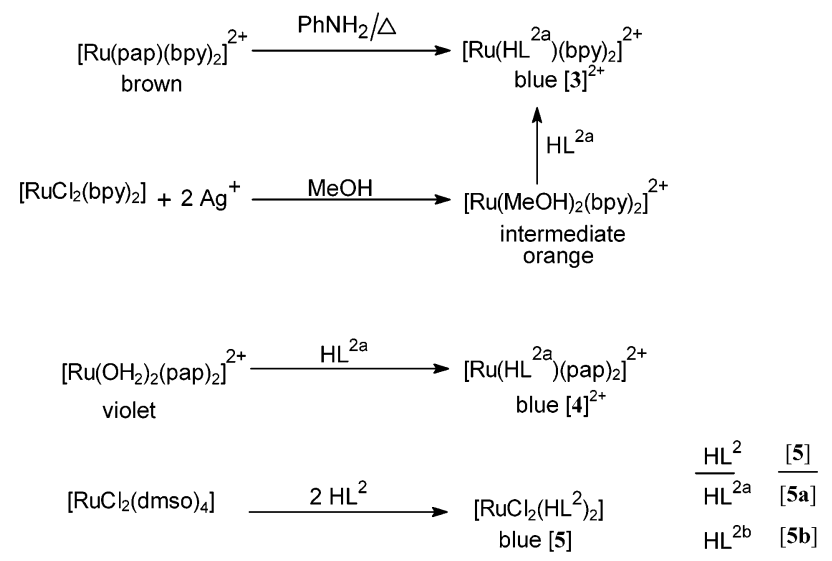

may be controlled by the proper selection of the mediator complex.

To have further insight into the ruthenium complexes of the $\mathrm{HL}^{2}$ ligand two more synthetic reactions (Scheme 3) were carried out using the preformed ligand $\mathrm{HL}^{2}$. The synthesis of the mixed ligand complexes $\mathbf{3}$ and $\mathbf{4}$ could be achieved in high yields from the reaction of $\left[\mathrm{Ru}(\mathrm{S})_{2}(\mathrm{~N} \wedge \mathrm{N})_{2}\right]^{2+}(S=$ solvent, $\mathrm{N} \wedge \mathrm{N}=$ bpy, pap), generated in situ, and the preformed $\mathrm{HL}^{2}$. The physicochemical properties of the two samples of $\mathbf{3}$ obtained from above two different routes (Scheme 3) are identical. The reaction of $\left[\mathrm{RuCl}_{2}\left(\mathrm{dmso}_{4}\right]\right.$ (dmso = dimethyl sulfoxide) with $\mathrm{HL}^{2}$ in 1:2 molar proportion produced a violet solution, which on purification produced crystalline $\left[\mathrm{RuCl}_{2}\left(\mathrm{HL}^{2}\right)_{2}\right](\mathbf{5})$ in $25 \%$ yield. The filtrate contained several overlapping blue and violet bands from which no pure product could be isolated so far. The cationic complexes $\mathbf{2}$ and $\mathbf{3}$, isolated as above, were formulated on the basis of their analytical as well as FAB mass spectral measurements. The positive ion FAB mass spectra of the two representatives $\mathbf{2 a}$ and $\mathbf{3}$ showed a peak each due to the $\left[\mathrm{M}-2 \mathrm{ClO}_{4}-\mathrm{H}\right]^{+}$at $\mathrm{m} / \mathrm{z} 924$ and 686 , respectively. These complexes are diamagnetic $\left(\mathrm{Ru}(\mathrm{II}), \mathrm{t}_{2}{ }^{6}\right)$. While cationic complexes $\mathbf{2 - 4}$ are 1:2 electrolytes, ${ }^{11}$ complex 5 is a nonelectrolyte in $\mathrm{CH}_{3} \mathrm{CN}$. In the resultant complexes, the transformed ligand $\mathrm{HL}^{2}$ bears an uncoordinated donor amine function, which is separated from a coordinated

(11) Greary, W. J. Coord. Chem. Rev. 1971, 7, 81. 


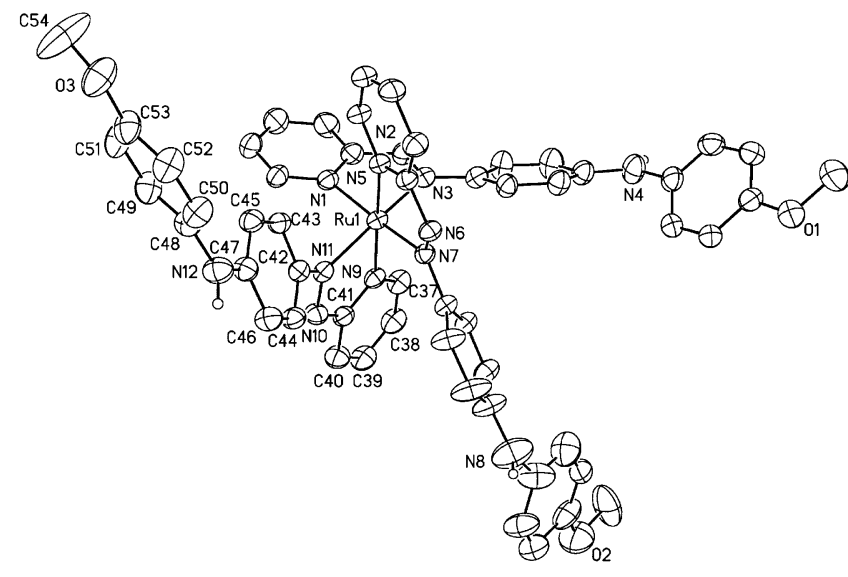

Figure 2. ORTEP representation of the cation $\left[\mathrm{Ru}\left(\mathrm{HL}^{2 \mathrm{c}}\right)_{3}\right]^{2+}$ in $\mathbf{2} \mathbf{c} \cdot \mathrm{C}_{7} \mathrm{H}_{8}$.

acceptor azo function by a conjugated spacer. Metal complexes of such ligands having both donor and acceptor chromophores are of current interest. ${ }^{12}$

C. Formulation and X-ray Structure of Complexes 2c and 5a. Compounds $\left[\mathrm{Ru}\left(\mathrm{HL}^{2 \mathrm{c}}\right)_{3}\right]\left(\mathrm{ClO}_{4}\right)_{2}(\mathbf{2 c})$ and $\left[\mathrm{RuCl}_{2}-\right.$ $\left.\left(\mathrm{HL}^{2 \mathrm{a}}\right)_{2}\right](\mathbf{5 a})$ formed $\mathrm{X}$-ray-quality crystals and were used for structure determination. The structure analysis of $\mathbf{2 c}$ indeed confirmed the regioselective fusion of $\mathrm{ArNH}_{2}$ to all three coordinated pap ligands of $\left[\mathrm{Ru}(\text { pap })_{3}\right]\left(\mathrm{ClO}_{4}\right)_{2}$ at the para-carbon of the pendant phenyl rings. A view of the cationic part of the molecule $\left[\mathrm{Ru}\left(\mathrm{HL}^{2 \mathrm{c}}\right)_{3}\right]\left(\mathrm{ClO}_{4}\right)_{2} \cdot \mathrm{C}_{7} \mathrm{H}_{8}$ is shown in Figure 2. In this complex, all three extended ligands $\mathrm{HL}^{2 \mathrm{c}}$ are identical and bind as neutral bidentate chelate. These ligands are formed, in situ, due to fusion of $(\mathrm{C}-\mathrm{N}$ bond formation) $p$-anisidine function to pap at the para position (relative to the azo fragment). The complex as a whole is dicationic, and the crystallographic asymmetric unit also contains two units of perchlorate and a toluene molecule as a solvate. The geometry of the cationic complex is meridional, which is similar to that of the starting $\left[\mathrm{Ru}(\mathrm{pap})_{3}\right]^{2+}$ (vide infra). Hence, the reaction is streoretentive. The chelate bite angles of $\left[\mathrm{HL}^{2 \mathrm{c}}\right]$ lie in the range $76.09(17)-76.80(17)^{\circ}$.

The bond distances (Table 1) indicate strong $\operatorname{Ru}(\mathrm{d} \pi)-$ $\mathrm{HL}^{2}(\mathrm{p} \pi)$ interactions in $\mathbf{2 c}$. These are primarily evidenced by lengthening of $\mathrm{N}-\mathrm{N}$ distances in the coordinating ligands. The $\mathrm{N}-\mathrm{N}$ distance is appreciably lengthened in $\left[\mathrm{Ru}\left(\mathrm{HL}^{2 \mathrm{c}}\right)_{3}\right]^{2+}$ (average 1.289(5) $\AA$ ) as compared ${ }^{4}$ to the $\mathrm{N}-\mathrm{N}$ distance $(1.264(2) \AA)$ in the uncoordinated $\mathrm{HL}^{2 \mathrm{a}}$ ligand. Coordination of $\mathrm{HL}^{2}$ to ruthenium (II) can lead to a decrease in the $\mathrm{N}-\mathrm{N}$ bond order due to both $\sigma$-donor and $\pi$-acceptor character of the ligand, the later character having a more pronounced ${ }^{10,13}$ effect. The relative shortness of the $\mathrm{Ru}(\mathrm{II})-\mathrm{N}\left(\mathrm{HL}^{2}\right)$ distances in $2 \mathrm{c}$ compared to the $\mathrm{Ru}(\mathrm{II})-\mathrm{N}$ distances in other ruthenium complexes ${ }^{9}$ of nitrogenous

(12) (a) Lacroix, P. G. Eur. J. Inorg. Chem. 2001, 339. (b) Bozec, H. L.; Renouazd, T. Eur. J. Inorg. Chem. 2000, 229. (c) Dhenaut, C.; Ledoux, I.; Samuel, I. D. W.; Zyss, J.; Bourgault, M.; Bozec, H. L. Nature 1995, 374, 339. (d) Zyss, J.; Ledoux, I. Chem. Rev. 1994, 94, 77.

(13) (a) Majumdar, P.; Kamar, K. K.; Castiñeiras, A.; Goswami, S. Chem. Commun. 2001, 1292. (b) Ghosh, B. K.; Mukhopadhyay, A.; Goswami, S.; Ray, S.; Chakravorty, A. Inorg. Chem. 1984, 23, 4633. (c) Lahiri, G. K.; Goswami, S.; Falvello, L. R.; Chakravorty, A. Inorg. Chem. 1987, 26, 3365. (d) Majumdar, P.; Peng, S.-M.; Goswami, S. J. Chem. Soc., Dalton Trans. 1998, 1569.

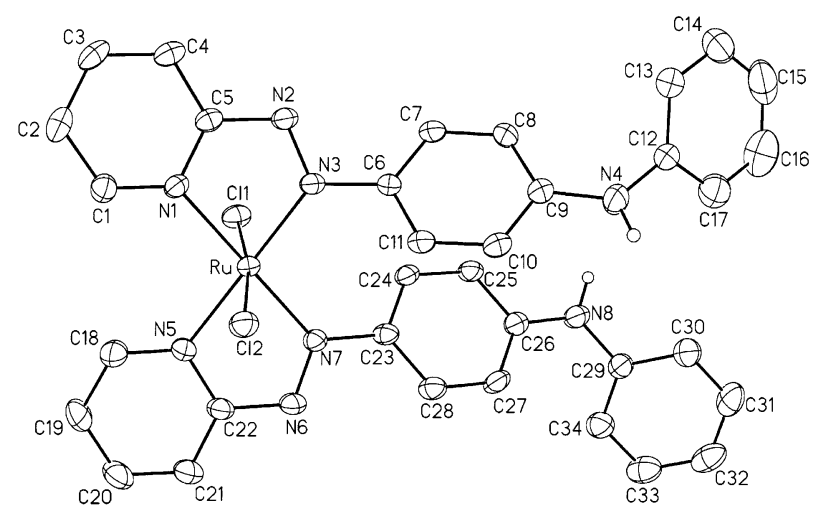

Figure 3. ORTEP representation of the molecular complex $\mathbf{5 a}$.

ligands is a further indication of the presence of strong $\mathrm{Ru}(\mathrm{II})-\mathrm{HL}^{2} \pi$-bonding.

Figure 3 shows the ORTEP and atom numbering scheme for the compound $\left[\mathrm{RuCl}_{2}\left(\mathrm{HL}^{2 \mathrm{a}}\right)_{2}\right](\mathbf{5 a})$. The ligand $\mathrm{HL}^{2 \mathrm{a}}$ is bidentate and chelates to ruthenium through the pyridine nitrogens $\mathrm{N}(1)$ and $\mathrm{N}(5)$ and the azo nitrogens $\mathrm{N}(3)$ and $\mathrm{N}(7)$. The amine nitrogens $\mathrm{N}(4)$ and $\mathrm{N}(8)$ remain protonated and uncoordinated. The binding mode of $\left[\mathrm{HL}^{2 \mathrm{a}}\right]$ in $\mathbf{5 a}$ is similar to that observed in 2c. The $\mathrm{HL}^{2}$ ligand lacks a 2-fold symmetry axis, and therefore, five geometrical isomers are possible ${ }^{14}$ for $\left[\mathrm{RuCl}_{2}\left(\mathrm{HL}^{2 \mathrm{a}}\right)_{2}\right]$. As noted before, we have been able to isolate only one of these isomers. The structural analysis of it indicates that compound 5a has the cholrides in trans configuration, but pyridine nitrogens as well as the coordinated azo nitrogens are in cis geometry. Such a configuration has been reported for two related complexes, $\left[\mathrm{RuCl}_{2}(\text { pap })_{2}\right]^{15}$ and $\left[\mathrm{RuCl}_{2}(\mathrm{~L})_{2}\right]^{16}(\mathrm{~L}=1$-tolyl-2-(phenylazo)imidazole). Strong stacking of the aromatic rings stabilizes this configuration. Notably, the $\mathrm{Ru}-\mathrm{N}$ (azo) lengths (average 2.006(3) $\AA$ ) are shorter than the $\mathrm{Ru}-\mathrm{N}($ py) lengths (average 2.078 (3) $\AA$ ). This may be attributed to strong $(\mathrm{d} \pi) \mathrm{Ru}-\mathrm{p} \pi(\mathrm{azo})$ interactions. As a consequence the $\mathrm{N}-\mathrm{N}$ length (average 1.298(4) $\AA$ ) in 5a is appreciably longer than that observed ${ }^{4}$ in the free ligand $(1.264(2) \AA)$.

The ${ }^{1} \mathrm{H}$ NMR spectra of the tris chelates $\mathbf{2}$ and $\mathbf{3}$ are very complex due to overlapping of unique proton resonances. The spectrum of $\mathbf{5}$, however, is resolved. The $\mathrm{N}-\mathrm{H}$ resonance was observed ${ }^{4}$ near $\delta 6.0$. Interestingly, each kind of proton in $\mathrm{HL}^{2}$ gave rise to one signal in $\mathbf{5}$. Thus, the two ligands in $\mathbf{5}$ are magnetically equivalent, for which a 2 -fold symmetry axis is required. The spectrum of a representative 5b is submitted as Supporting Information (Figure S1).

D. Optical Spectra. One of the most important observations in the IR spectra of the complexes of $\mathrm{HL}^{2}$ is the appearance ${ }^{17}$ of $v(\mathrm{~N}-\mathrm{H})$ in the range $3420-3250 \mathrm{~cm}^{-1}$. The dihalo complexes showed sharp bands, while those for the tris chelates are broad. The abilities of the azo ligands to act

(14) (a) Mitra, K. N.; Goswami, S. Inorg. Chem. 1997, 36, 1322. (b) Choudhury, S.; Goswami, S. Polyhedron 1996, 15, 1191.

(15) Velders, A. H.; Kooijman, H.; Spek, A. L.; Haasnoot, J. G.; Vos, D. d.; Reedijk, J. Inorg. Chem. 2000, 39, 2966.

(16) Misra, T. K.; Das, D.; Sinha, C.; Ghosh, P.; Pal, C. K. Inorg. Chem. 1998, $37,1672$.

(17) Mitra, K. N.; Choudhury, S.; Castiñeiras, A.; Goswami, S. J. Chem. Soc., Dalton Trans. 1998, 2901. 
Das et al.

Table 2. Optical Spectral Data

\begin{tabular}{|c|c|c|c|c|c|}
\hline \multirow[b]{2}{*}{ compd } & \multicolumn{4}{|c|}{$\operatorname{IR}(\mathrm{KBr})\left(v, \mathrm{~cm}^{-1}\right)$} & \multirow[b]{2}{*}{$\operatorname{abs}^{a}\left[\lambda_{\max }, \mathrm{nm}\left(\epsilon, \mathrm{M}^{-1} \mathrm{~cm}^{-1}\right)\right]$} \\
\hline & $v(\mathrm{~N}-\mathrm{H})$ & $v(\mathrm{C}=\mathrm{C}+\mathrm{C}=\mathrm{N})$ & $v(\mathrm{~N}=\mathrm{N})$ & $v\left(\mathrm{ClO}_{4}\right)$ & \\
\hline 2a & 3410 & 1580 & 1300 & 1140,640 & $593(48$ 810), 496 (34 480), $282(39480)$ \\
\hline 2b & 3390 & 1590 & 1295 & 1140,645 & $602(65510), 494^{b}(44510), 284(55340)$ \\
\hline $2 c$ & 3380 & 1590 & 1295 & 1150,630 & $608(59430), 498^{b}(40120), 284(46470)$ \\
\hline 2d & 3410 & 1580 & 1300 & 1120,645 & $595(46670), 500^{b}(32990), 284(45450)$ \\
\hline 3 & 3400 & 1580 & 1300 & 1110,630 & 569 (19 690), 500 (22 270), 283 (57 740) \\
\hline 4 & 3420 & 1580 & 1290 & 1110,630 & 603 (17 410), 509 (11 680), 370 (17 110) \\
\hline $5 \mathbf{a}$ & 3250 & 1585 & 1285 & & $606(26070), 482^{b}(19460), 290(35030)$ \\
\hline $5 \mathbf{b}$ & 3260 & 1590 & 1280 & & $620(26740), 484^{b}(21460), 290(34420)$ \\
\hline
\end{tabular}

${ }^{a}$ Solvent $\mathrm{CH}_{3} \mathrm{CN} .{ }^{b}$ Shoulder.

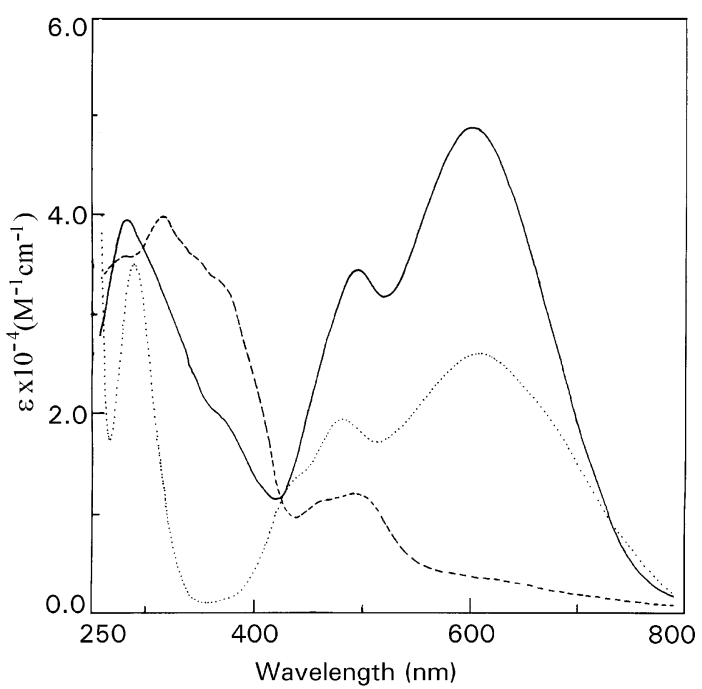

Figure 4. Electronic spectra of the complexes: $1(--)$; $2 \mathbf{a}(-) ; \mathbf{5 a}(\cdots)$.

as strong $\pi$-acceptors toward low valent metal ions are well documented. ${ }^{18}$ The azo imine orbitals in these complexes are strongly involved in $\pi$-interactions. Thus, the $v(\mathrm{~N}=\mathrm{N})$ stretching frequencies in the complexes of $\mathrm{HL}^{2}$ are appreciably lowered ${ }^{8,15}$ as compared to that for the free $\mathrm{HL}^{2}$. Selected IR data are collected in Table 2.

The solution color of all the ruthenium complexes of $\mathrm{HL}^{2}$ is blue, and these are characterized by a strong absorption near $600 \mathrm{~nm}$. The solution spectral data are collected in Table 2. The spectrum of the free ligand, $\mathrm{HL}^{2 \mathrm{a}}$, consists of two high-energy transitions at 415 and $270 \mathrm{~nm}$, respectively. The $\mathrm{UV}-$ vis spectrum of the cationic tris chelate, $\left[\mathrm{Ru}\left(\mathrm{HL}^{2}\right)_{3}\right]^{2+}$, comprises a strong absorption in the range $590-610 \mathrm{~nm}$, which is associated with a shoulder near $500 \mathrm{~nm}$. There is also a strong band in the UV region. The intensity of the lowest energy transition in these complexes is unusually high, which vary with the change of substitution $\mathrm{R}$ on the ligand $\mathrm{HL}^{2}$. For example, the intensities of the $600 \mathrm{~nm}$ bands of $\left[\mathrm{Ru}\left(\mathrm{HL}^{2 \mathrm{a}}\right)_{3}\right]^{2+}$ and $\left[\mathrm{Ru}\left(\mathrm{HL}^{2 \mathrm{~b}}\right)_{3}\right]^{2+}$ are 48810 and $65510 \mathrm{M}^{-1}$ $\mathrm{cm}^{-1}$, respectively. Such highly intense transitions were noted before $^{12}$ in some related systems containing donor-acceptor functions. Representative spectra of the parent $\left[\mathrm{Ru}(\mathrm{pap})_{3}\right]^{2+}$, $\left[\mathrm{Ru}\left(\mathrm{HL}^{2 \mathrm{a}}\right)_{3}\right]^{2+}$, and $\left[\mathrm{RuCl}_{2}\left(\mathrm{HL}^{2 \mathrm{a}}\right)_{2}\right]$ are displayed in Figure 4 for comparison. The broad transition at $492 \mathrm{~nm}$ for $\left[\mathrm{Ru}(\text { pap })_{3}\right]^{2+}$ was assigned to a metal-to-ligand ${ }^{6}$ charge transfer (MLCT) transition. Comparison of the above spectra indicates that the MLCT transition in $\left[\mathrm{Ru}\left(\mathrm{HL}^{2 \mathrm{~b}}\right)_{3}\right]^{2+}$ also appeared at $494 \mathrm{~nm}$. The band near $600 \mathrm{~nm}$ is due to an additional allowed transition, which is responsible for the intense blue color of its solution. Interestingly, the mixedligand compound $\left[\mathrm{Ru}\left(\mathrm{HL}^{2 \mathrm{a}}\right)(\mathrm{pap})_{2}\right]^{2+}$ also showed a transition at $603 \mathrm{~nm}$, which is accompanied by a MLCT transition ${ }^{8 \mathrm{c}}$ at $509 \mathrm{~nm}$. Notably, the intensity of the $603 \mathrm{~nm}$ transition in the later example is about 3-fold less intense than that observed in $\left[\mathrm{Ru}\left(\mathrm{HL}^{2 \mathrm{a}}\right)_{3}\right]^{2+}$. We thus ascribe this lowest energy transition (near $600 \mathrm{~nm}$ ) in the complexes of $\mathrm{HL}^{2}$ as the intraligand charge-transfer transition. ${ }^{11 \mathrm{~b}}$ The ligand $\mathrm{HL}^{2}$ has the donor amine as well as the azo acceptor functions, which are separated by a conjugated spacer. The acceptor property of the azo-chromophore is augmented upon coordination to the ruthenium center. An interesting trend with respect to the lowest energy transitions in two pairs of the following complexes is noted. In the order from $\gamma$-[ $\left[\mathrm{RuCl}_{2}-\right.$ $\left.(\text { pap })_{2}\right]^{8 \mathrm{c}}$ to $\left[\mathrm{Ru}(\text { pap })_{3}\right]^{2+},{ }^{6}$ the MLCT transition shifts appreciably from 635 to $492 \mathrm{~nm}$. In comparison, there is only very little shift of the lowest energy transition in moving from 5 to $\mathbf{2}$ (Figure 4). It may be noted that the geometries of $\mathbf{5}$ and $\mathbf{2}$ are identical with those of the two above compounds, viz. $\gamma-\left[\mathrm{RuCl}_{2}(\text { pap })_{2}\right]$ and $\left[\mathrm{Ru}(\text { pap })_{3}\right]^{2+}$, respectively.

E. Redox Properties. The redox behavior of the complexes were studied by using cyclic voltammetry (CV) and differential pulse voltammetry (DPV) in acetonitrile $(0.1 \mathrm{M}$ $\left.\mathrm{NEt}_{4} \mathrm{ClO}_{4}\right)$ in the potential range 1.8 to $-2.5 \mathrm{~V}$ by using platinum and glassy carbon working electrodes. The reported potentials (Table 3) are referenced to the saturated calomel electrode (SCE). The value for the ferrocenium-ferrocene couple, under our experimental conditions, was $0.42 \mathrm{~V}$.

All the tris chelates of $\mathrm{HL}^{2}$, reported in this work, showed multiple reversible cathodic waves. The anodic wave however, was irreversible. The free ligand, $\mathrm{HL}^{2 \mathrm{a}}$ displays two reductive waves at -1.11 and $-1.69 \mathrm{~V}$, which are cathodic, compared to pap. This may be attributed to the strong inductive $(+\mathrm{I})$ effect of the arylamino substitution in $\mathrm{HL}^{2}$. Thus, for the tris-chelates $\left[\mathrm{Ru}\left(\mathrm{HL}^{2}\right)_{3}\right]^{2+}$ six reductions, in principle, are expected. In practice, all six reductions were indeed observable in the tris chelates. The processes were generally reversible except the wave for the final step, which appears to be quasireversible or irreversible. The cyclic voltammogram of a representative compound, $\mathbf{2 d}$, is submitted as a Supporting Information (Figure S2). The observation of a complete set of six reductions in the tris chelate is rare. ${ }^{19}$ In the case of mixed pap $-\mathrm{HL}^{2}$ complex, $\left[\mathrm{Ru}\left(\mathrm{HL}^{2 \mathrm{a}}\right)(\mathrm{pap})_{2}\right]^{2+}$ (4), all six reductions were observed, but in $\left[\mathrm{Ru}\left(\mathrm{HL}^{2 \mathrm{a}}\right)\right.$ - 
Table 3. Electrochemical Data ${ }^{a}$

\begin{tabular}{|c|c|c|c|c|}
\hline compd & $\operatorname{oxidn} E_{\mathrm{p}}, \mathrm{V}^{b}$ & $\operatorname{redn}-E_{1 / 2}, \mathrm{~V}\left(\Delta E_{\mathrm{p}}, \mathrm{mV}\right)^{c}$ & $\Delta E^{\circ}{ }_{\mathrm{ox}} /{ }_{\mathrm{red}}, \mathrm{V}^{d}$ & $v_{\mathrm{ct}}, \mathrm{V}^{e}$ \\
\hline $2 \mathbf{a}$ & 1.35 & $0.17(100), 0.45(80), 0.89(80), 1.53(90), 1.84(100), 2.04^{f}(100)$ & 1.52 & 2.09 \\
\hline 2b & 1.25 & $0.25(120), 0.52(100), 0.96(100), 1.59(150), 1.99(140), 2.12^{f}(90)$ & 1.50 & 2.06 \\
\hline $2 c$ & 1.15 & $0.19(110), 0.48(100), 0.91(90), 1.53(90), 1.93(80), 2.09^{f}(90)$ & 1.34 & 2.04 \\
\hline 2d & 1.41 & $0.11(110), 0.40(110), 0.84(90), 1.48(90), 1.86(110), 2.10^{f}(110)$ & 1.52 & 2.08 \\
\hline 3 & 1.28 & $0.51(80), 1.20(80), 1.57(110), 1.77(110)$ & 1.79 & 2.18 \\
\hline 4 & 1.33 & $0.06(80), 0.40(130), 0.85(110), 1.48(180), 1.79^{f}(200), 2.14^{f}(190)$ & 1.39 & 2.06 \\
\hline 5a & 1.09 & $0.72, g^{g} 0.92,{ }^{g} 1.49,{ }^{g} 1.87^{g}$ & & \\
\hline $5 \mathbf{b}$ & $0.76^{h}(70), 1.19$ & $0.71,{ }^{g} \quad 0.93,{ }^{g} \quad 1.47,,^{g} 1.90^{g}$ & & \\
\hline
\end{tabular}

${ }^{a}$ Conditions: solvent, acetonitrile; supporting electrolyte, $\mathrm{NEt}_{4} \mathrm{ClO}_{4}(0.1 \mathrm{M})$; working electrode, platinum for oxidation and glassy carbon for reduction processes; reference electrode, SCE; solute concentration, ca. $10^{-3} \mathrm{M}$; scan rate, $50 \mathrm{mV} \mathrm{s}{ }^{-1} .{ }^{b}$ Anodic peak potential. The irreversible response without cathodic counterpart. ${ }^{c} \mathbf{E}_{1 / 2}$ is calculated as the average of anodic (Epa) and cathodic (Epc) peak potentials; $\Delta E_{\mathrm{p}}=\left(E_{\mathrm{pa}}-E_{\mathrm{pc}}\right)$. An $E_{1 / 2}$ value indicates the redox process is reversible. ${ }^{d}$ Refers to the difference in the formal potentials for the first oxidation and the first reduction processes. ${ }^{e}$ Observed lowest energy charge-transfer transitions in V (see Table 2). ${ }^{f}$ Quasireversible. ${ }^{g}$ Irreversible $E_{\mathrm{pc} .}{ }^{h}$ Reversible oxidation process.

$\left.(\text { bpy })_{2}\right]^{2+}(\mathbf{3})$, the last two were inaccessible (see Supporting Information Figures S4 and S3). This is not surprising since the reductions of bpy are expected ${ }^{6,19}$ to occur at more cathodic potentials than that of pap. It is believed that in complex $\mathbf{3}$ the $\mathrm{HL}^{2 \mathrm{a}}$ ligand is reduced completely before the bpy reduction occurs. Each one of the tris chelates also showed an irreversible anodic wave near 1.1-1.4 V, which is ascribed to ligand oxidation processes. The dihalo complex $\left[\mathrm{RuCl}_{2}\left(\mathrm{HL}^{2 \mathrm{~b}}\right)_{2}\right]$ showed a reversible anodic response at $0.76 \mathrm{~V}$ followed by an irreversible wave at $1.2 \mathrm{~V}$. There are multiple irreversible cathodic responses in the range -0.70 to -1.90 V. A similar nature for the voltammogram was observed ${ }^{8 c}$ for $\gamma-\left[\operatorname{RuCl}_{2}(\text { pap })_{2}\right]$. The reversible anodic wave in the complex of the unsubstituted ligand $\left[\mathrm{RuCl}_{2}\left(\mathrm{HL}^{2 \mathrm{a}}\right)_{2}\right](5 \mathbf{a})$ was absent; however, the pattern of the voltammogram in the remaining potential region is similar to that observed for $\left[\mathrm{RuCl}_{2}\left(\mathrm{HL}^{2 \mathrm{~b}}\right)_{2}\right](\mathbf{5 b})$. The reversible oxidative wave might have shifted anodic in $\mathbf{5 a}$ in the absence of a donor $(-\mathrm{Me})$ substituion and was thus not observed before the irreversible wave.

Notably, the lowest energy charge-transfer transitions in the complexes of $\mathrm{HL}^{2}$ correlates linearly ${ }^{19}$ with $\Delta E^{\circ}$ ox/red (Table 3), where $\Delta E^{\circ}{ }_{\text {ox/red }}$ refers to the difference in the formal potentials for the first oxidation and the first reduction processes.

\section{Conclusion}

In this work we have achieved regioselective paraamination at all three coordinated 2-(phenylazo)pyridine ligands in $\left[\mathrm{Ru}(\mathrm{pap})_{3}\right]^{2+}$. The role of the mediator complex with respect to site selectivity of the amination reaction has been established. Thus, for a labile complex, an ortho-fusion process is favored. This seems reasonable since prior coordination of an amine residue at the vacant site of the metal ion would bring it in close proximity to the ortho- $\mathrm{CH}$ of the pendent phenyl ring. In the absence of any such vacant site at the metal center, as it occurs in the case of a substitutionally inert mediator complex, $\mathrm{ArNH}_{2}$ cannot approach the ortho-carbon and hence fusion occurs only at

(18) (a) Kharmawphlang, W.; Choudhury, S.; Deb, A. K.; Goswami, S. Inorg. Chem. 1995, 34, 3828. (b) Krause, R. A.; Krause, K. Inorg. Chem. 1980, 19, 2600. (c) Ackermann, M. N.; Barton, C. R.; Deodene, C. J.; Specht, E. M.; Keill, S. C.; Schreiber, W. E.; Kim, H. Inorg. Chem. 1989, 28, 397.

(19) Ghosh, B. K.; Chakravorty, A. Coord. Chem. Rev. 1989, 95, 239. the para-carbon. The generality of the fusion reaction was established by the use of different $\mathrm{ArNH}_{2}$ species. The products were completely characterized. The aminated ligand $\mathrm{HL}^{2}$, thus formed, has both donor and acceptor chromophores and shows interesting optical as well as redox properties. Further work on similar transformations, with the use of other aromatic amines having additional functionalities such as 4-aminopyridine, is under active search. It is anticipated that the product of such reactions might be useful for the construction of polymetallic systems.

\section{Experimental Section}

Materials. The starting complexes $\left[\mathrm{Ru}(\mathrm{pap})_{3}\right]\left(\mathrm{ClO}_{4}\right)_{2},{ }^{6}\left[\mathrm{RuCl}_{2}-\right.$ (dmso $\left.)_{4}\right],{ }^{20}\left[\mathrm{RuCl}_{2}(\mathrm{bpy})_{2}\right],{ }^{21}$ and $\left[\mathrm{Ru}\left(\mathrm{H}_{2} \mathrm{O}\right)_{2}(\mathrm{pap})_{2}\right]\left(\mathrm{ClO}_{4}\right)_{2}{ }^{8 \mathrm{a}}$ and the ligand $\mathrm{HL}^{24}$ were synthesized by the published procedures. Solvents and chemicals used for synthesis were of analytical grade. The supporting electrolyte (tetraethylammonium perchlorate) and solvents for electrochemical work were obtained as before. ${ }^{6}$

Physical Measurements. A JASCO V-570 spectrometer was used to record the electronic spectra. Infrared spectra were recorded with a Perkin-Elemer 783 spectrophotometer. A Perkin-Elmer 240C elemental analyzer was used for microanalysis. ${ }^{1} \mathrm{H}$ NMR spectra were measured in $\mathrm{CDCl}_{3}$ with a Bruker Avance DPX 300 spectrometer, and $\mathrm{SiMe}_{4}$ was used as the internal standard. Electrochemical measurements were done under a dry nitrogen atmosphere on a PAR 370-4 electrochemistry system as described before. ${ }^{6}$ All potentials in this work are referenced to the saturated calomel electrode (SCE) and are uncorrected for junction contribution. The value for the ferrocenium-ferrocene couple under our experimental condition was $0.42 \mathrm{~V}$.

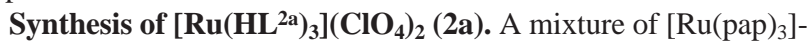
$\left(\mathrm{ClO}_{4}\right)_{2}(0.20 \mathrm{~g}, 0.23 \mathrm{mmol})$ and $\mathrm{PhNH}_{2}(0.5 \mathrm{~mL})$ was heated on a steam bath for $4 \mathrm{~h}$. The initial brown color of the mixture gradually became ink-blue. The mixture was cooled and washed thoroughly with diethyl ether for several times. Finally, it was purified on a preparative TLC plate using a $40 \%$ chloroform-acetonitrile mixture as the eluent. The intense blue product, thus obtained, was recrystallized from a toluene-acetonitrile mixture. Yield: $0.19 \mathrm{~g}$, 70\%. Anal. Calcd for $\mathrm{C}_{51} \mathrm{H}_{42} \mathrm{~N}_{12} \mathrm{Cl}_{2} \mathrm{O}_{8} \mathrm{Ru}$ : C, $54.55 ; \mathrm{H}, 3.77 ; \mathrm{N}$, 14.97. Found: C, 54.32; H, 3.54; N, 14.76. MS: $m / z, 924$.

Compounds $\mathbf{2 b}-\mathbf{2 d}$ were prepared similarly by following the above procedure using the appropriate substituted aromatic amines in place of $\mathrm{PhNH}_{2}$. The yields and analytical data are collected below.

(20) Evans, I. P.; Spencer, A.; Wilkinson, G. J. Chem. Soc., Dalton Trans. 1973, 204.

(21) Giordana, P. J.; Bock, C. R.; Wrighton, M. S. J. Am. Chem. Soc. 1978, $100,6960$. 
Table 4. Crystallographic Data for $\mathbf{1}, \mathbf{2} \cdot \mathbf{c}_{7} \mathrm{C}_{8}$, and $\mathbf{5 a}$

\begin{tabular}{|c|c|c|c|}
\hline & 1 & $2 \mathbf{c} \cdot \mathrm{C}_{7} \mathrm{H}_{8}$ & $5 a$ \\
\hline empirical formula & $\mathrm{C}_{33} \mathrm{H}_{27} \mathrm{Cl}_{2} \mathrm{~N}_{9} \mathrm{O}_{8} \mathrm{Ru}$ & $\mathrm{C}_{61} \mathrm{H}_{56} \mathrm{Cl}_{2} \mathrm{~N}_{12} \mathrm{O}_{11} \mathrm{Ru}$ & $\mathrm{C}_{34} \mathrm{H}_{28} \mathrm{Cl}_{2} \mathrm{~N}_{8} \mathrm{Ru}$ \\
\hline . & 849.61 & 1305.15 & 720.61 \\
\hline temp, $\mathrm{K}$ & $293(2)$ & $293(2)$ & $295(2)$ \\
\hline cryst syst & monoclinic & triclinic & monoclinic \\
\hline space group & $P 2_{1} / c$ & $P \overline{1}$ & $P 2_{1} / n$ \\
\hline$a, \AA$ & $9.2701(13)$ & $12.5390(7)$ & $11.444(3)$ \\
\hline$b, \AA$ & $9.7631(14)$ & $14.5309(8)$ & $21.150(4)$ \\
\hline$c, \AA$ & $38.926(6)$ & $18.5892(11)$ & $13.234(3)$ \\
\hline$\alpha, \operatorname{deg}$ & 90 & 75.7620 & 90 \\
\hline$\beta, \mathrm{d}$ & 3.8 & 80. & 106.2 \\
\hline$\gamma, \mathrm{d}$ & 90 & $71.4670(10)$ & 90 \\
\hline$V, \AA^{3}$ & $3515.0(9)$ & $3097.1(3)$ & $3074.9(11)$ \\
\hline$D_{\text {calc }}, \mathrm{Mg} / \mathrm{m}^{3}$ & 1.605 & 1.400 & 1.557 \\
\hline 7 & 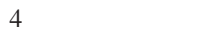 & 2 & 4 \\
\hline $\begin{array}{l}\text { cryst dimens, } \\
\mathrm{mm}^{3}\end{array}$ & $\begin{array}{c}0.20 \times 0.08 \\
\times 0.06\end{array}$ & $\begin{array}{c}0.61 \times 0.22 \\
\times 0.06\end{array}$ & $\begin{array}{c}0.30 \times 0.16 \\
\times 0.10\end{array}$ \\
\hline $\begin{array}{l}\theta \text { range for data } \\
\text { collcn, deg }\end{array}$ & $1.05-27.54$ & $1.14-27.55$ & $1.87-25.00$ \\
\hline GOF & 1.03 & & 1.001 \\
\hline & 0 & 1 & 5422 \\
\hline unique reflcns & 8038 & 13721 & 5422 \\
\hline final $\mathrm{R}$ indices & $\mathrm{R} 1=0.069$ & $\mathrm{R} 1=0.068$ & $\mathrm{R} 1=0.0355$ \\
\hline$[I>2 \sigma(I)]$ & $\mathrm{wR} 2=0.1358$ & $\mathrm{wR} 2=0.2097$ & $\mathrm{wR} 2=0.0669$ \\
\hline
\end{tabular}

2b. Yield: $65 \%$. Anal. Calcd for $\mathrm{C}_{54} \mathrm{H}_{48} \mathrm{~N}_{12} \mathrm{Cl}_{2} \mathrm{O}_{8} \mathrm{Ru}$ : C, 55.67; H, 4.15; N, 14.43. Found: C, 55.33; H, 4.46; N, 14.56.

2c. Yield: $70 \%$. Anal. Calcd for $\mathrm{C}_{54} \mathrm{H}_{48} \mathrm{~N}_{12} \mathrm{Cl}_{2} \mathrm{O}_{11} \mathrm{Ru}$ : C, 53.47; H, 3.99; N, 13.86. Found: C, 53.27; H, 3.88; N, 13.76.

2d. Yield: $63 \%$. Anal. Calcd for $\mathrm{C}_{51} \mathrm{H}_{39} \mathrm{~N}_{12} \mathrm{Cl}_{5} \mathrm{O}_{8} \mathrm{Ru}$ : C, 49.95; H, 3.20; N, 13.71. Found: C, 49.73; H, 3.60; N, 13.88 .

Synthesis of $\left[\mathrm{Ru}\left(\mathrm{HL}^{2 \mathrm{a}}\right)(\mathrm{bpy})_{2}\right]\left(\mathrm{ClO}_{4}\right)_{2}$ (3). Method A. A mixture of $\left[\mathrm{Ru}(\right.$ pap $\left.)(\mathrm{bpy})_{2}\right]\left(\mathrm{ClO}_{4}\right)_{2}(0.20 \mathrm{~g}, 0.25 \mathrm{mmol})$ and aniline $(0.5 \mathrm{~mL})$ was heated for $5 \mathrm{~h}$ at $125-130{ }^{\circ} \mathrm{C}$ on an oil bath. The resultant dull violet colored mixture was cooled and washed with diethyl ether for several times. The crude mass was recrystallized 3 times from an acetonitrile-toluene mixture. Finally, the compound was purified by preparative TLC technique using a $40 \%$ chloroform-acetonitrile mixture as the eluent. The pure compound was separated as a blue-violet band. Yield: $0.08 \mathrm{~g}, 36 \%$. Anal. Calcd for $\mathrm{C}_{37} \mathrm{H}_{30} \mathrm{~N}_{8} \mathrm{Cl}_{2} \mathrm{O}_{8} \mathrm{Ru}$ : C, 50.12; H, 3.41; N, 12.64. Found: C, 50.18; H, 3.68; N, 13.02.

Method B. A mixture of $\left[\mathrm{RuCl}_{2}(\mathrm{bpy})_{2}\right]\left(\mathrm{ClO}_{4}\right)_{2}(0.20 \mathrm{~g}, 0.41$ mmol) and $\mathrm{AgNO}_{3}(0.14 \mathrm{~g}, 0.82 \mathrm{mmol})$ was refluxed in $50 \mathrm{~mL}$ of methanol for $1 \mathrm{~h}$ to generate $\left[\mathrm{Ru}(\mathrm{bpy})_{2}(\mathrm{MeOH})_{2}\right]^{2+}$. The solution was cooled and filtered through a Whatman 42 filter paper to remove the precipitated $\mathrm{AgCl}$. Ligand $\mathrm{HL}^{2 \mathrm{a}}(0.11 \mathrm{~g}, 0.41 \mathrm{mmol})$ was then added to the orange filtrate, and it was further refluxed for $1.5 \mathrm{~h}$. The solution became blue-violet. It was concentrated to $15 \mathrm{~mL}$, and $0.5 \mathrm{~mL}$ of saturated aqueous solution of $\mathrm{NaClO}_{4}$ was added to precipitate the compound. The crude product was then purified by slow diffusion of the solution of the compound in acetonitrile into toluene. This process was repeated 3 times to get pure crystalline product. Yield: $0.24 \mathrm{~g}, 65 \%$. Anal. Calcd for $\mathrm{C}_{37} \mathrm{H}_{30} \mathrm{~N}_{8} \mathrm{Cl}_{2} \mathrm{O}_{8} \mathrm{Ru}:$ C, 50.12; H, 3.41; N, 12.64. Found: C, 49.78; H, 3.48; N, 12.75. MS: $\mathrm{m} / \mathrm{z} 686$.

Synthesis of $\left[\mathrm{Ru}\left(\mathrm{HL}^{2 \mathrm{a}}\right)(\mathrm{pap})_{2}\right]\left(\mathrm{ClO}_{4}\right)_{2}$ (4). A mixture of $\left[\mathrm{Ru}\left(\mathrm{H}_{2} \mathrm{O}\right)_{2}(\text { pap })_{2}\right]\left(\mathrm{ClO}_{4}\right)_{2}(0.20 \mathrm{~g}, 0.28 \mathrm{mmol})$ and $\mathrm{HL}^{2 \mathrm{a}}(0.08 \mathrm{~g}$, $0.28 \mathrm{mmol})$, in $60 \mathrm{~mL}$ of dehydrated ethanol, was refluxed on a steam bath for $4 \mathrm{~h}$. The initial violet color slowly became yellowish green with the precipitation of a gummy mass. The mixture was cooled and filtered. The greenish filtrate was discarded. The dark crude mass was recrystallized 4 times from a dichloromethanehexane mixture. The microcrystalline compound, thus obtained, was finally purified by slow diffusion of the solution of the compound in acetonitrile into toluene. This crystallization process was repeated twice. Yield: $0.17 \mathrm{~g}, 63 \%$. Anal. Calcd for $\mathrm{C}_{39} \mathrm{H}_{32} \mathrm{~N}_{10} \mathrm{Cl}_{2} \mathrm{O}_{8} \mathrm{Ru}: \mathrm{C}$, 49.79; H, 3.43; N, 14.89. Found: C, 49.51; H, 3.61; N, 14.73. MS: $m / z 741$.

Synthesis of [ $\left.\operatorname{RuCl}_{2}\left(\mathbf{H L}^{2 \mathrm{a}}\right)_{2}\right]$ (5a). To a methanolic solution of $\mathrm{HL}^{2 \mathrm{a}}(0.22 \mathrm{~g}, 0.82 \mathrm{mmol})$ was added a sample of $\left[\mathrm{RuCl}_{2}(\mathrm{dmso})_{4}\right]$ $(0.20 \mathrm{~g}, 0.41 \mathrm{mmol})$. The mixture was refluxed on a steam bath for $4 \mathrm{~h}$. The color of the solution changed from orange yellow to blue violet with the precipitation of a crystalline blue compound. The reaction mixture was then allowed to cool to room temperature. The crystalline blue product was collected by filtration, which was washed with methanol and dichloromethane. The compound was finally recrystallized by slow evaporation of its DMF solution. Yield: 0.09 g, 30\%. Anal. Calcd for $\mathrm{C}_{34} \mathrm{H}_{28} \mathrm{~N}_{8} \mathrm{Cl}_{2} \mathrm{Ru}$ : C, 56.67; H, 3.92; N, 15.55. Found: C, 56.60; H, 3.61; N, 15.41. MS: $m / z$ 719. The filtrate from the above reaction mixture showed the presence of several blue and violet overlapping bands on the TLC plate, from which no pure compound could be isolated so far.

The compound $\left.\left[\mathrm{RuCl}_{2}\left(\mathrm{HL}^{2 \mathrm{~b}}\right)_{2}\right] \mathbf{( 5 b}\right)$ was synthesized similarly using $\mathrm{HL}^{2 \mathrm{~b}}$ in place of $\mathrm{HL}^{2 \mathrm{a}}$. Yield: $25 \%$. Anal. Calcd for $\mathrm{C}_{36} \mathrm{H}_{32} \mathrm{~N}_{8^{-}}$ $\mathrm{Cl}_{2} \mathrm{Ru}$ : C, 57.75; H, 4.31; N, 14.97. Found: C, 57.81; H, 4.07; N, 15.27 .

X-ray Structure Determination. We obtained suitable X-rayquality crystals of compound $\mathbf{1}$ by slow diffusion of toluene into a dichloromethane solution of the compound. The suitable X-rayquality crystals of $\mathbf{2} \mathbf{c}$ were grown by slow diffusion of toluene into an acetonitrile solution of the compound. Intensity data for both the above compounds $\mathbf{1}$ and $\mathbf{2 c}$ were measured on a Bruker SMART diffractometer (Mo K $\alpha$ radiation, $\lambda=0.71073 \AA$ ), and data were corrected for Lorentz-polarization effects. Both the structures were solved by employing SHELXS-9722 program package and refined by full-matrix least squares based on $F^{2}$ (SHELXL-97). ${ }^{23}$ All hydrogen atoms of the ligands were added in calculated positions. X-ray-quality cryastals of $\mathbf{5 a}$ were obtained by slow evaporation of a solution of $\mathbf{5 a}$ in dimethylformamide. The data for $\mathbf{5 a}$ were collected on a Nonius CAD4 diffractometer (Mo K $\alpha$ radiation, $\lambda$ $=0.71073 \AA$ ). The data were corrected for Lorentz-polarization effects. The structure was solved by using the SHELXS-97 program package and refined by full-matrix least-squares based on $F^{2}$ (SHELXL-97). Hydrogen atoms were added in the calculated positions. All the relevant data are given in Table 4

Acknowledgment. Financial support received from the Department of Science and Technology and the Council of Scientific and Industrial Research, New Delhi, is gratefully acknowledged. Thanks are due to the RSIC, Lucknow, India, for providing mass spectra. We are thankful to Dr. Samaresh Bhattacharya for the help.

Supporting Information Available: X-ray crystallographic details, in CIF format, of the three compounds $\mathbf{1}, \mathbf{2 c}$, and $\mathbf{5 a}$, the ${ }^{1} \mathrm{H}$ NMR spectrum of $\mathbf{5 b}$, and segmented cyclic voltammograms of the compounds $\mathbf{2 d}, \mathbf{3}$, and $\mathbf{4}$. This material is available free of charge via the Internet at http://pubs.acs.org.

IC0203724

(22) Sheldrick, G. M. Acta Crystallogr., Sect. A 1990, 46, 467.

(23) Sheldrick, G. M. SHELXL 97. Program for the refinement of crystal structures; University of Goettingen: Goettingen, Germany, 1997. 